Zhirong Fu, Srinivas Akula, Michael Thorpe and Lars Hellman*

\title{
Marked difference in efficiency of the digestive enzymes pepsin, trypsin, chymotrypsin, and pancreatic elastase to cleave tightly folded proteins
}

https://doi.org/10.1515/hsz-2020-0386

Received December 16, 2020; accepted April 30, 2021; published online May 12, 2021

\begin{abstract}
In order for the intestinal mucosa to absorb dietary proteins they have to be digested into single amino acids or very short peptides of a length of not more than four amino acids. In order to study the efficiency of the digestive endopeptidases to digest folded proteins we have analyzed several target proteins under different conditions, native proteins, heat denatured and acid treated. The three pancreatic serine proteases, trypsin, chymotrypsin, and pancreatic elastase, were found to be remarkable inefficient in cleaving native folded proteins whereas pepsin, which acts at a very low $\mathrm{pH}$ ( $\mathrm{pH} 1.2)$ was much more efficient, possibly due to the denaturing conditions and thereby better accessibility to internal cleavage sites at the low $\mathrm{pH}$. Heat treatment improved the cleavage considerably by all three pancreatic enzymes, but acid treatment followed by return to neutral $\mathrm{pH}$ did not have any major effect. Cleavage at the low $\mathrm{pH}$ when the protein is in a denatured state, is apparently very efficient. This indicates that pepsin is the prime enzyme cleaving the properly folded native proteins and that the pancreatic enzymes primarily are involved in generating single amino acids or very short peptides for efficient uptake by the intestinal mucosa.
\end{abstract}

Keywords: chymotrypsin; digestive enzymes; digestive system; pancreatic elastase; pepsin; trypsin.

\footnotetext{
*Corresponding author: Lars Hellman, Department of Cell and Molecular Biology, Uppsala University, Uppsala, The Biomedical Center, Box 596, S-751 24 Uppsala, Sweden, E-mail: Lars.Hellman@icm.uu.se. https://orcid.org/0000-00031459-3815
}

Zhirong Fu, Srinivas Akula and Michael Thorpe, Department of Cell and Molecular Biology, Uppsala University, Uppsala, The Biomedical Center, Box 596, S-751 24 Uppsala, Sweden

\section{Introduction}

To efficiently use proteins as a food source they have to be transformed into single amino acids or very short peptides of a length of not more than four amino acids. This is performed by a number of different proteases of our digestive system. Polysaccharides start to be enzymatically digested already by the saliva, which contains the enzyme amylase, whereas proteins are first attacked by proteases in the stomach (Chauncey et al. 1963; Janiak 2016; Meisler and Ting 1993). In the stomach the acidic environment denatures the proteins, which most likely has an important role in making internal peptide bonds more accessible for cleavage. The hydrochloric acid released by the acid glands of the stomach lowers the $\mathrm{pH}$ to below two. The protease of this intestinal compartment is pepsin, an aspartic protease with a $\mathrm{pH}$ optimum of between $\mathrm{pH} 1$ and 2 , and therefore optimized for the environment in the stomach (Janiak 2016; Kageyama 2002). Following the digestion in the stomach, the fully or partly digested food enters the small intestine. There the $\mathrm{pH}$ is returned to neutral $\mathrm{pH}$ by the secretion of bicarbonate from duct cells of the pancreas (Ishiguro et al. 2012). When the food passes the duodenum a number of proteases also enter the intestinal canal from the pancreas (Goettig et al. 2019; Guyonnet et al. 1999). There are enzymes with multiple specificities including both endo- and exopeptidases. The endopeptidases have specificities for different amino acids at the P1 site, the amino acid after which the enzyme cleaves. Trypsin cleaves after basic (positively charged) amino acids, chymotrypsin after aromatic amino acids and pancreatic elastase after aliphatic amino acids and after polar residues such as Ser and Thr. There are also several carboxypeptidases that cleave at the carboxy terminal end of the proteins.

In a recent study of proteases that are expressed by immune cells, we have observed that they are strongly affected by the folding of the protein for efficient cleavage. Sites exposed on the surface were targeted by these enzymes, whereas optimal sites were left uncleaved if hidden in the structure (Fu et al. 2017). Our study therefore showed 
that accessibility is a major factor for efficient cleavage by these enzymes. Our question was therefore how similar or dissimilar the digestive enzymes are when it comes to folding. These hematopoietic serine proteases belong to the same protease family as the pancreatic serine proteases, trypsin, chymotrypsin, and pancreatic elastase. We decided to study four of the digestive enzymes for their cleavages of native properly folded proteins to see if this feature of these endopeptidases was a more general characteristic; a factor that may have a major impact on the evolution of an acidic environment and enzymes active at a low $\mathrm{pH}$, as a prominent part of the digestive tract of most multicellular organisms.

\section{Results}

\section{Target molecules}

To study the importance of folding on the cleavage of dietary proteins we first used a type of target protein used to study cleavage specificity; a recombinant protein consisting of two copies of the tightly folded Escherichia coli redox protein, thioredoxin (Trx) (Figure 1A). In a linker region between these two copies a kinker region was inserted consisting of a few repeated Gly-Ser motifs and a nine amino acid region with a sequence susceptible for cleavage by an enzyme with trypsin, chymotrypsin, or elastase specificity, respectively (Figure $1 \mathrm{~A}$ and $\mathrm{B}$ ). Following the second Trx, a region with six His residues for easy purification of the recombinant protein on IMAC $\mathrm{Ni}^{2+}$ chelating columns was inserted (Figure 1A). The benefit of this system is that one can simultaneously analyze cleavage of an open and a closed structurally-folded region in one experiment; the linker region is open and linear whereas the Trx domains are tightly folded. This type of substrate has been very successful in obtaining quantitative information concerning the importance of amino acids at and surrounding the cleavage site of a number of hematopoietic serine proteases, and on thrombin (Gallwitz et al. 2010, 2012; Thorpe et al. 2012, 2016, 2018a,b). As examples of a native folded protein the cleavage of bovine serum albumin (BSA), chicken egg albumin (ovalbumin), and for the cleavage by pepsin also a sample of cow saliva were included.

\section{Cleavage by pepsin at $\mathrm{pH} 1.2$}

We first analyzed the cleavage by pepsin at $\mathrm{pH} 1.2$, which is the physiological $\mathrm{pH}$ for this enzyme, of three different $2 x \operatorname{Trx}$ substrates, one with a linker region with a trypsin

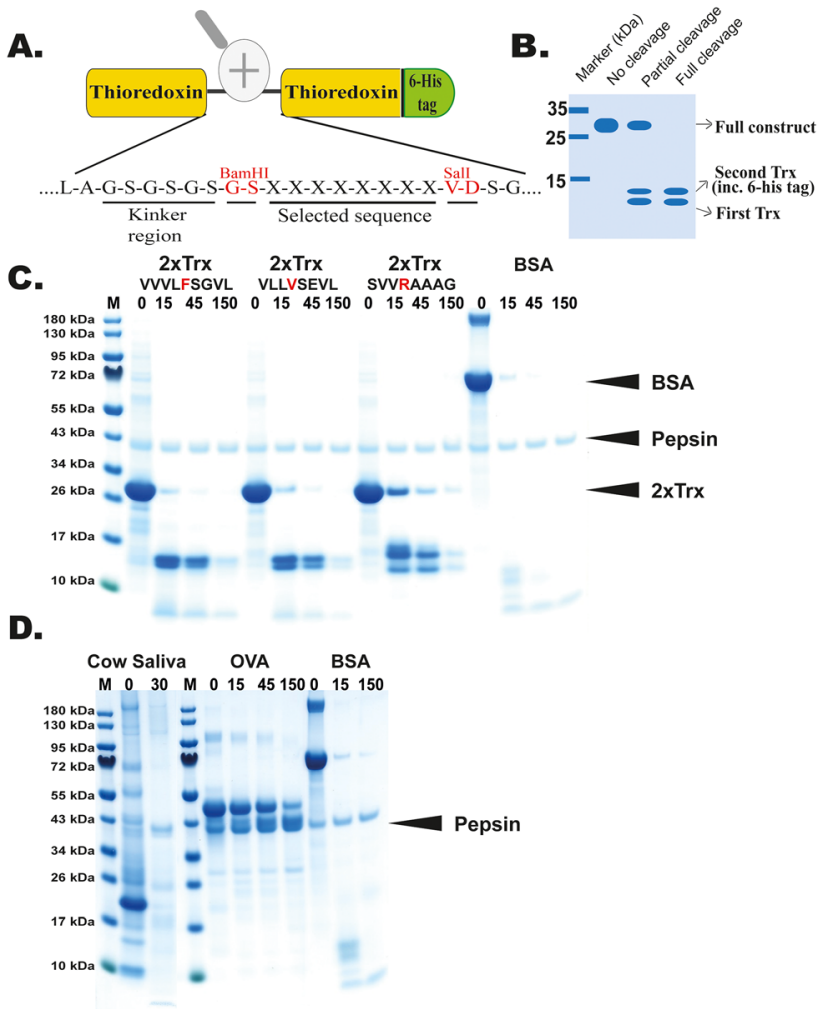

Figure 1: Cleavage of target molecules by pepsin at $\mathrm{pH}$ 1.2. The efficiency in cleavage by pepsin at its physiologic $\mathrm{pH}$ was analyzed against three different $2 x$ Trx substrates as well as BSA, ovalbumin and deglycosylated whole bovine saliva. The cleavage was performed in glycine buffer at pH 1.2. (A) A schematic picture of the $2 x \operatorname{Trx}$ construct where the region inserted by double-stranded oligonucleotides is marked by 'selected sequence'. The sequences inserted and analyzed for cleavage by pepsin in panel $C$ are listed above each cleavage reaction, (B) a schematic picture of a standard cleavage reaction. Bands at $\sim 28 \mathrm{kDa}$ represent uncleaved two-thioredoxin (Trx) protein and the two bands present at $14 \mathrm{kDa}$ represent cleaved protein, with the upper of the two bands representing the Trx containing the $\mathrm{His}_{6}$-tag. Sequences above the panels in panel $C$ represent the inserted octamers and numbers represent the reaction time in minutes, $(C)$ analysis of the cleavage of three different $2 x \operatorname{Trx}$ substrates and of BSA by pepsin. The linker region of the $2 x \operatorname{Trx}$ substrates were almost completely cleaved after only $15 \mathrm{~min}$ and the tightly folded Trx domains were almost completely cleaved after $150 \mathrm{~min}$. BSA was efficiently cleaved already after $15 \mathrm{~min}$, and (D) analysis of the cleavage of total bovine saliva (deglycosylated) and of chicken egg ovalbumin by pepsin. The saliva was incubated with pepsin for $30 \mathrm{~min}$ and the ovalbumin for 15,45 , and $150 \mathrm{~min}$. As ovalbumin was only partially digested, BSA cleaved with the same enzyme for 15 and $150 \mathrm{~min}$ was included in the assay to verify that the enzyme used to cleave ovalbumin was active.

susceptible sequence, one with a chymotrypsin and one with an elastase susceptible sequence (Figure 1C). The trypsin sequence has an Arg in central position, the chymotrypsin sequence a Phe in central position and the elastase sequence a Val in that position (Figure 1C). 
The linker region was cleaved slightly faster than the tightly folded Trx sequences, however, both were almost completely hydrolyzed after $150 \mathrm{~min}$ of incubation (Figure 1C). BSA was also very efficiently cleaved and almost no visible traces after $150 \mathrm{~min}$ of incubation (Figure 1C). Here, pepsin was shown to be very efficient in cleaving both linear and tightly folded structures, which is a key characteristic of efficient food digestion. Pepsin was also analyzed for the cleavage of cow saliva that had been treated with a panel of deglycosylation enzymes to allow the proteins to more easily enter the gel as the content of highly glycosylated mucins make the saliva viscous. The deglycosylated saliva was the cleaved with pepsin for $30 \mathrm{~min}$ and as can be seen from the figure almost all the proteins were almost completely digested (Figure 1D). We also analyzed the cleavage of ovalbumin by pepsin and to our surprise ovalbumin showed a quite different behavior. One part of the protein was rapidly digested whereas one other part was remarkably stable against the action of pepsin indicating that this part of the molecule has a structure quite compact and stable even at $\mathrm{pH}$ 1.2, showing that some proteins may resist the cleavage by pepsin at $\mathrm{pH}$ 1.2. For these assays we used an enzyme to substrate ratio of approximately 1-10 as also can be seen from the gel (Figure 1). The enzyme is visible as a faint band compared to the more abundant targets (Figure 1).

\section{Cleavage of $2 x T r x$ substrates by trypsin, chymotrypsin, and pancreatic elastase at $\mathrm{pH}$}

\section{2}

The cleavage of $2 x \operatorname{Trx}$ substrates with a preferred linker region for respective enzyme(s) was analyzed at the physiological $\mathrm{pH}$ of the duodenum, which is estimated to be around $\mathrm{pH}$ 7. A trypsin substrate with a central Arg was used for trypsin, a chymotrypsin substrate with a central Phe for chymotrypsin and an elastase substrate with a central Val for the pancreatic elastase were used to determine the difference in cleavage activity on linear versus tightly folded regions of the substrate (Figure $2 \mathrm{~A}-\mathrm{C}$ ). These substrates were analyzed under three different conditions. In the first panel, the enzyme and substrate mixture were incubated without any pre-treatment. In the second panel, the protein had first been heat denatured at $95^{\circ} \mathrm{C}$ for $10 \mathrm{~min}$ after which the temperature was returned to $37^{\circ} \mathrm{C}$ for the cleavage analysis. In the third panel, the target protein had been incubated at $\mathrm{pH} 2.0$ for $30 \mathrm{~min}$ where after the sample

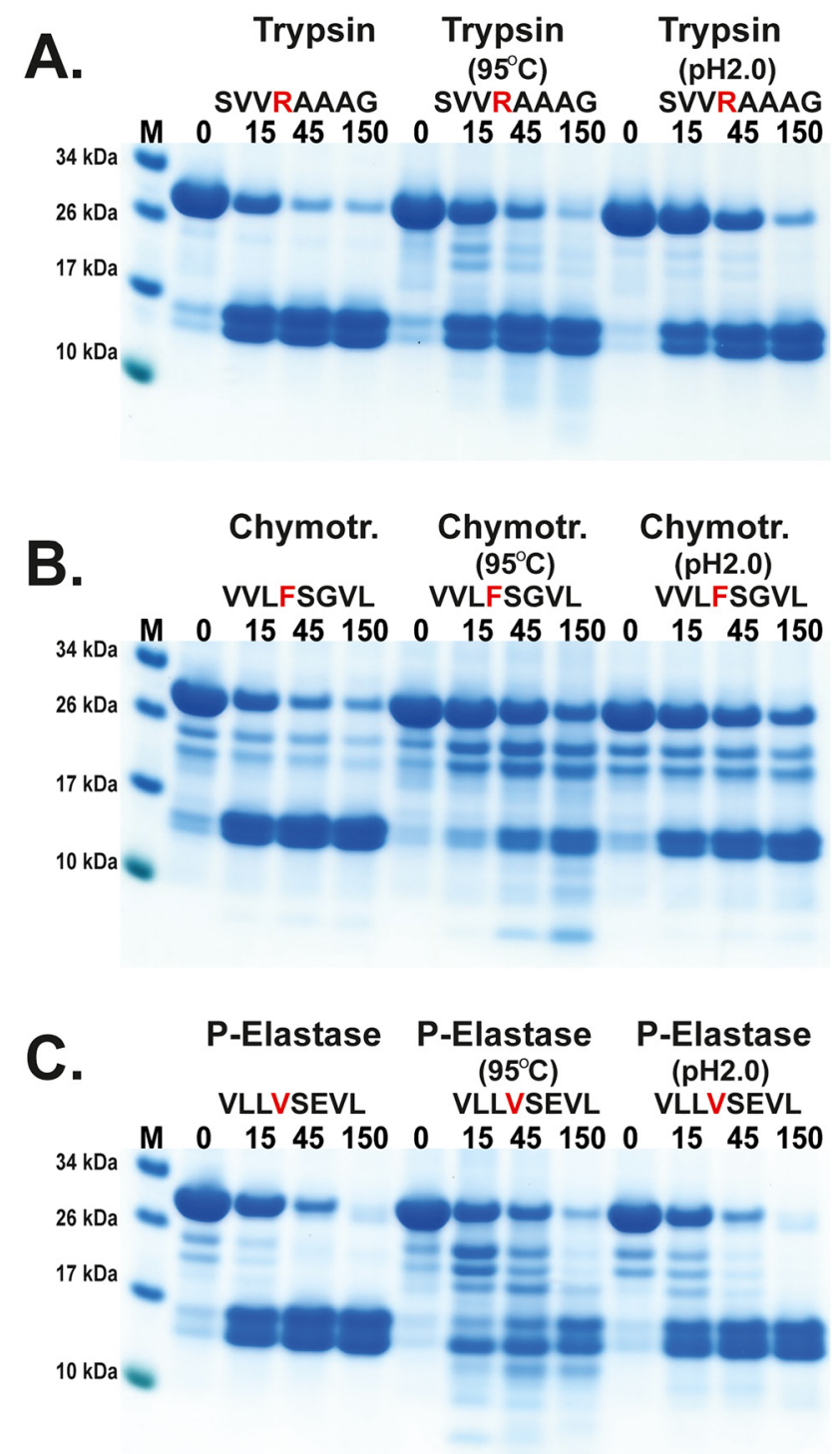

Figure 2: Cleavage of 2xTrx substrates by chymotrypsin, pancreatic elastase, and trypsin at $\mathrm{pH} 7.2$, after different pretreatments of the substrate.

Three different substrates, one each for the three different pancreatic serine proteases were used to determine the difference in cleavage efficiency of linear and tightly folded substrates by these enzymes. The cleavage was performed without pretreatment, after a 10 min incubation at $95^{\circ} \mathrm{C}$ and after a 30 min incubation at $\mathrm{pH}$ 2.0. (A) Cleavage by trypsin, (B) cleavage by chymotrypsin, and (C) cleavage by pancreatic elastase. The linker regions were very efficiently cleaved after $15 \mathrm{~min}$, whereas the tightly folded Trx domains were almost untouched even after $150 \mathrm{~min}$, both in the absence of pretreatment and after a short $\mathrm{pH}$ drop to $\mathrm{pH}$ 2.0. However, the heat denaturation seems to give a substantial improvement in the cleavage also of the Trx domains by chymotrypsin and elastase but only a minor effect on the cleavage by trypsin. To show the specificity in target selection of the three enzymes we analyzed their cleavage of a panel of 2xTrx substrates with different $\mathrm{P} 1$ residues. 
was $\mathrm{pH}$ adjusted back to neutral $\mathrm{pH}$ at 7.2 for cleavage analysis. The results showed the linker regions were efficiently cleaved by all three enzymes already at $15 \mathrm{~min}$ of incubation, whereas the tightly folded regions were very resistant to digestion by all three enzymes (Figure 2). A preincubation at $\mathrm{pH} 2.0$ for $30 \mathrm{~min}$ did not markedly change this pattern (Figure 2B). However, heat denaturation significantly affected the cleavage, most likely due to partly denaturing the protein, which would open target sites for more efficient cleavage. We also observed a reduced cleavage of the linker region for both trypsin and chymotrypsin, possibly due to denaturation of the protein may have resulted in shielding of the open structure of the linker region. The ration between enzyme and target was approximately 500 times for trypsin, 300 times for chymotrypsin, and 25 for pancreatic elastase. These values were chosen based on the activity against the linker region in initial experiments to obtain the best discriminating concentrations for the assay. This gives also indications to the overall activity of the different enzymes indicating considerably higher activity, per molar basis, of trypsin and chymotrypsin compared to pancreatic elastase and pepsin.

To confirm the correct cleavage sites within the linker region between the two Trx molecules all three enzymes were analyzed with a panel of $2 x \operatorname{Trx}$ substrates with different $\mathrm{P} 1$ residues. As can be seen from the figure trypsin only cleaves the substrate with a centrally positioned Arg and not the chymase nor the elastase substrates (Figure 3A). Similarly, chymotrypsin only cleaves the substrate with a centrally positioned aromatic amino acid (Figure 3B). In contrast, the pancreatic elastase was found to be more unrestrictive and also cleave at other amino acids than only the classical aliphatic residues, Val, Ile, and Ala or in the region of the linker close to the $\operatorname{Trx}$ sequences (Figure 3C).

\section{Cleavage of BSA and ovalbumin by chymotrypsin, and by a mix of trypsin, chymotrypsin, and pancreatic elastase at pH 7.2}

The cleavage of BSA and ovalbumin by chymotrypsin and by a mix of all three pancreatic serine proteases, trypsin, chymotrypsin, and pancreatic elastase was analyzed after different pretreatments of the substrate. The left panels of Figure $4 \mathrm{~A}$ and $\mathrm{B}$ shows the cleavage without any pretreatment. The middle panels show the cleavage after heat denaturation for $10 \mathrm{~min}$ at $95^{\circ} \mathrm{C}$ and the right panels after a 30 min incubation at $\mathrm{pH} 2.0$ and then returned to neutral $\mathrm{pH}$ for cleavage. BSA and ovalbumin were quite resistant to cleavage by chymotrypsin and even resistant to cleavage by a mix of all three enzymes (Figure 4A and B). Almost no effect on cleavage was seen after a pretreatment at low $\mathrm{pH}$ but a marked effect was seen after heat denaturation, similar to what was observed with the $2 x \operatorname{Trx}$ substrates (Figure 2).

\section{Discussion}

Folded proteins were found to be relatively resistant to cleavage by the pancreatic serine proteases, even by a mix of all three of them (Figures 2 and 4). In contrast, pepsin and the cleavage at low $\mathrm{pH}$ seemed to be extremely efficient in the digestion of both linear and tightly folded structures (Figure 1). Pretreatment of the substrates by lowering the $\mathrm{pH}$, which would occur if the food passes through the stomach before entering the duodenum, did also not seems to induce a significant opening of the structure for more efficient digestion by the pancreatic serine proteases. In contrast, heat treatment was relatively efficient in making

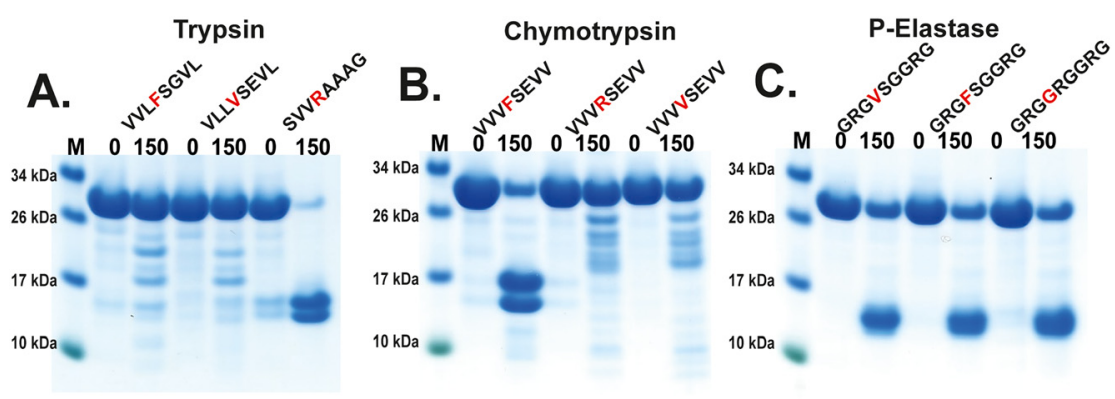

Figure 3: Cleavage of 2xTrx substrates by chymotrypsin, pancreatic elastase and trypsin at pH 7.2, to show target preference. As shown in (A) trypsin only cleaves the substrate with a positively charged Arg in the P1 position and as shown in (B) chymotrypsin only cleaves a substrate with an aromatic amino acid in the $\mathrm{P} 1$ position. In contrast and as shown in (C) pancreatic elastase is less discriminative and cleaves also substrates lacking the classical aliphatic amino acids, Val, Ile, and Ala and probably also in parts of the linker region close to the Trx sequences. 

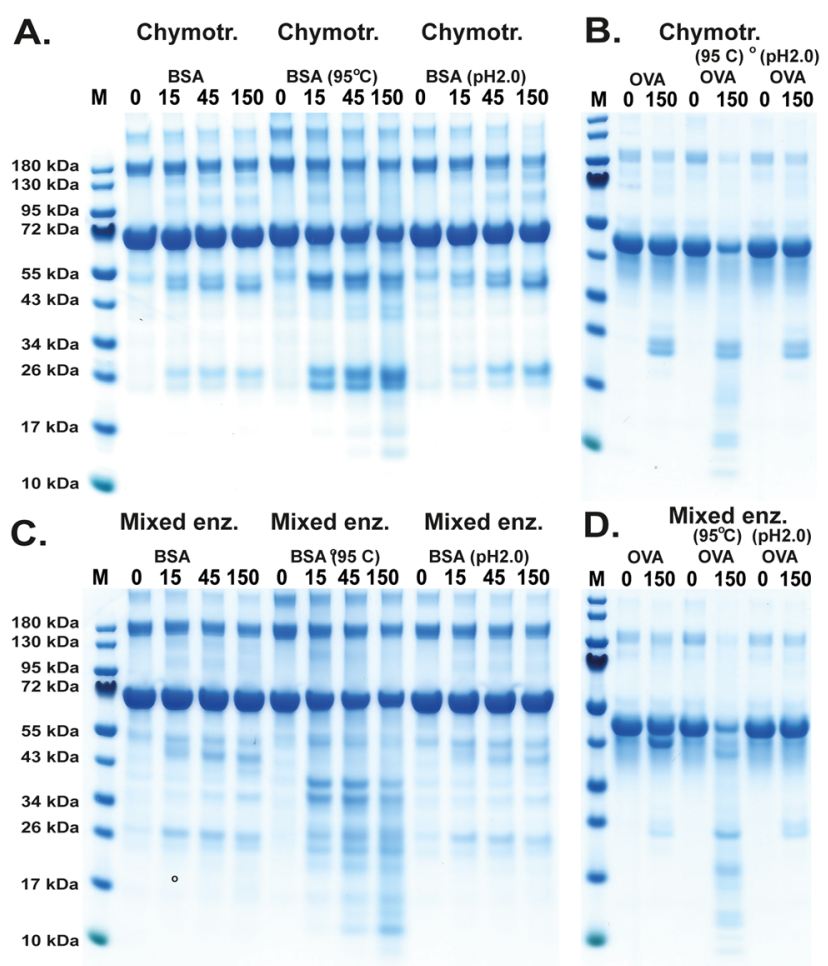

Figure 4: Cleavage of BSA and ovalbumin by chymotrypsin, pancreatic elastase, and trypsin at pH 7.2 under different conditions.

(A) BSA and (B) ovalbumin were cleaved by chymotrypsin and ( $C$ and D) by a mix of the three pancreatic enzymes. The cleavage was performed without pretreatment, after a $10 \mathrm{~min}$ incubation at $95^{\circ} \mathrm{C}$ and after a $30 \mathrm{~min}$ incubation at $\mathrm{pH}$ 2.0.

the substrates more accessible for these enzymes. Both of these findings stand to reason; food digestion at low $\mathrm{pH}$, and by an enzyme that has its optimum at this low $\mathrm{pH}$, is very common among multicellular organisms, indicating that it has been an evolutionary successful strategy for food uptake. Heat denaturation of food has also been claimed to have been a major step in human development, to be able to better absorb the nutrients of protein-rich food and thereby a key factor in the development of a large and energy dependent brain (Carmody et al. 2011).

What is then the role of the pancreatic serine proteases and the carboxy-peptidases if pepsin does the major work in protein digestion? Amino acid and peptide transporters of the small intestine have been found to only take up peptides of a size of four amino acids or smaller, and even the size of four amino acids is less efficiently absorbed compared to shorter peptides making the subsequent cleavage of small peptides generated by pepsin into very short peptides or single amino acids very important. It is therefore possible that the major function of the pancreatic proteases is to complete the job performed by pepsin. The need for multiple primary specificities and a combination of endo- and exopeptidases does seem logical. We would need an array of different primary specificities to cleave these small peptides where some may not contain a positively charged amino acid and thereby not cleaved by trypsin. Some would not contain an aromatic amino acid and thereby not cleaved by chymotrypsin and some would not contain an aliphatic amino acid and thereby not cleaved by the elastase. However, by a combination of these three, and together with the exopeptidases, most peptides would be suitable targets for one or more of these enzymes. The final step is then carried out by membranebound brush border peptidases of the intestinal mucosa and cytoplasmic proteases of the epithelial cells. The brush border enzymes are a number of integral membrane proteins that convert the small peptides to single amino acids or very small peptides (Goodman 2010; Hooton et al. 2015; McConnell et al. 2011). The free amino acids or the very short peptides are then imported into the epithelial cells by sodium-dependent amino acid transporters, one each for basic, acidic, and neutral amino acids (Goodman 2010; Spanier and Rohm 2018). These transporters bind the amino acids only after also binding sodium. Following binding of both sodium and peptide, the transporter goes through a conformational change and pumps in both the sodium and the amino acid into the cytoplasm of the enterocyte. Di- and tripeptides can also be transported into the enterocyte by co-transport with $\mathrm{H}^{+}$ions by another transporter the PepT1 (Goodman 2010; Spanier and Rohm 2018). Following uptake of the di- and tripeptides, these peptides are further digested by cytoplasmic proteases within the enterocyte. The free amino acids are then transported into the blood by another transporter that sits at the basolateral membrane of the enterocyte. This transporter does not need a sodium gradient. Only a very small number of the peptides enter the blood.

In conclusion, pepsin, which was very efficient in cleaving even tightly folded proteins, seems to very important for the initial step in the absorption of food proteins and to be an evolutionary old and successful strategy for food uptake (Janiak 2016). The possibility to act at a low denaturing $\mathrm{pH}$ appeared to be important for efficient cleavage of the otherwise tightly folded proteins, which seemed to be difficult to access by the pancreatic enzymes. This pattern is very similar to what we previously observed for the hematopoietic serine proteases, which were highly dependent on accessibility of the potential cleavage sites for efficient cleavage (Fu et al. 2017). The pancreatic enzymes may therefore have a major function to perform the second step in the digestion of the food proteins by reducing the size of the peptides generated by 
pepsin. Both hematopoietic and pancreatic endopeptidases thereby seem to show many similarities concerning the effect of folding on the efficiency of substrate cleavage. As a third and fourth step, the brush border enzymes and the cytoplasmic proteases of the enterocytes finish the sequence by cleaving the small peptides into single amino acids for final transport into the blood.

We could also show that some proteins are remarkable resistant to the cleavage by pepsin at $\mathrm{pH} 1.2$, as shown for one part of ovalbumin and for pepsin itself, so some proteins may have an amino acid composition that makes them more compact and thereby more stable at low $\mathrm{pH}$. However, we could also see that after heat treatment ovalbumin was relatively efficiently cleaved by a combination of the pancreatic enzymes indicating that the combination of the different digestive enzymes, pepsin and the pancreatic enzymes, are of importance for the cleavage of the majority of proteins of the food.

It is also important to say that although pepsin is very efficient in cleaving tightly folded proteins and that an acidic environment and proteases that are able to act efficiently at this low $\mathrm{pH}$ persons with complete gastrectomy can live a relatively normal life indicating pepsin hydrolysis is not absolutely necessary for survival and that a combination of the pancreatic enzymes can be sufficient when acting together for our survival (Goodman 2010).

\section{Materials and methods}

\section{Enzymes}

Digestive enzymes used for analysis were all purchased from Sigma-Aldrich (Sigma-Aldrich Sweden AB, Stockholm, Sweden): Pepsin A from porcine gastric mucosa (Sigma P-6887), $\alpha$-Chymotrypsin from bovine pancreas (Sigma C-3142), Beta-trypsin from bovine pancreas (Sigma T-1426), and Elastase (Pancreatopeptidase E) from porcine pancreas (Sigma E-1250). Chymotrypsin and trypsin were dissolved with PBS, while pepsin was dissolved with $0.1 \mathrm{M} \mathrm{HCl}, 1 \% \mathrm{NaCl}$ (pH 1.2).

\section{Target molecules}

A new type of recombinant substrate was used to study the importance of folding on the cleavage of dietary proteins. Two copies of the E. coli Trx gene were inserted in tandem into the $\mathrm{pET}$ - 21 vector. Between the two Trx molecules, a nine amino acid region was inserted with a sequence susceptible for cleavage by trypsin, chymotrypsin, or elastase respectively. For purification a $\mathrm{His}_{6}$-tag was also inserted in the $\mathrm{C}$-terminal. The sequences of the individual clones were verified after cloning by sequencing of both DNA strands. The plasmids were then transformed into the $E$. coli Rosetta gami strain for protein expression (Novagen, Merck, Darmstadt, Germany). A $10 \mathrm{ml}$ overnight culture of transformed expression clone was diluted 10 times in LB + ampicillin and grown for $1-2 \mathrm{~h}$ at $37^{\circ} \mathrm{C}$ until the $\mathrm{OD}(600 \mathrm{~nm})$ reached 0.5 . IPTG was then added to a final concentration of $1 \mathrm{mM}$. The culture was subsequently grown at $37{ }^{\circ} \mathrm{C}$ for an additional $3 \mathrm{~h}$. After incubation, the bacteria were pelleted by centrifugation at $3000 \mathrm{rpm}$ for $12 \mathrm{~min}$. The pellet was then washed once with $25 \mathrm{ml}$ PBS $+0.05 \%$ Tween 20 and then resuspended in $2 \mathrm{ml} \mathrm{PBS}$. The pellet was sonicated $5 \times 30 \mathrm{~s}$ to open the cells. The lysate was centrifuged at 13,000 rpm for $3 \mathrm{~min}$ and the supernatant was transferred to a new tube. Five hundred microliters of Ni-NTA slurry (50:50) (Qiagen, Hilden, Germany) was added and the sample was gently rotated for $45 \mathrm{~min}$ at $4^{\circ} \mathrm{C}$. The Ni-NTA beads were then transferred to a $2 \mathrm{ml}$ column and were washed with $1 \mathrm{ml}$, then 2 and $2 \mathrm{ml}$ of washing buffer (PBS $+0.05 \%$ Tween $20+20 \mathrm{mM}$ imidazole). Protein was then eluted by adding $100 \mu \mathrm{l}$ elution buffer followed by five additional $200 \mu \mathrm{l}$ volumes of elution buffer (PBS $+0.05 \%$ Tween $20+100 \mathrm{mM}$ imidazole). Each fraction was collected individually and $10 \mu \mathrm{l}$ from each elution fraction was then mixed with $2.5 \mu \mathrm{l}$ of $4 \times$ LDS loading buffer for SDS-PAGE analysis (Invitrogen, Carlsbad, CA, USA). The fractions containing the most protein were pooled together and the concentration of the combined fractions was then determined by BioRad DC Protein assay (Bio-Rad Laboratories Hercules, CA, USA).

\section{Cleavage reactions}

Approximately $25 \mu \mathrm{g}$ of recombinant $2 \mathrm{xTrx}$ protein or BSA was added to each $50 \mu$ l cleavage reaction (in PBS). For the cleavage analysis of heat denatured proteins, $25 \mu \mathrm{g}$ recombinant 2-Trx protein or BSA in $50 \mu \mathrm{l}$ PBS was pre-heated at $95^{\circ} \mathrm{C}$ for $10 \mathrm{~min}$. For the cleavage analysis of acid denatured proteins, $25 \mu \mathrm{g}$ recombinant $2 \mathrm{xTrx}$ protein in elution buffer or $25 \mu \mathrm{g}$ BSA in $\mathrm{H}_{2} \mathrm{O}$ was firstly adjusted with $0.1 \mathrm{M} \mathrm{HCl}$ to $\mathrm{pH} 2.0$ and incubated for $30 \mathrm{~min}$. Five $\mu \mathrm{l}$ of $10 \times \mathrm{PBS}$ and $0.1 \mathrm{M} \mathrm{NaOH}$ were then added to adjust the $\mathrm{pH}$ back to 7.2 . Sterile $\mathrm{H}_{2} \mathrm{O}$ was finally added to $50 \mu \mathrm{l}$ in total. Native or denatured 2xTrx proteins, BSA, deglycosylated cow saliva, or ovalbumin was then mixed with active enzyme ( $48 \mathrm{ng}$ of trypsin or $80 \mathrm{ng}$ of chymotrypsin or $2 \mu \mathrm{g}$ of pancreatic elastase or $4.2 \mathrm{ug}$ [or $16 \mathrm{U}$ ] of pepsin). Based on gel intensity the ratio between pepsin and target molecule seems to be close to 1-10 which is a slightly higher value compared to the value of the enzyme concentration given by the distributing company. The reaction was kept at room temperature during the entire experiment and $10 \mu \mathrm{l}$ of sample was removed at the indicated time points $(0,15,45$, and $150 \mathrm{~min})$ and the reaction was terminated by addition of $2.5 \mu \mathrm{l}$ of $4 \times$ sample buffer and $0.5 \mathrm{ul}$ $\beta$-mercaptoethanol. The samples were then heat treated for $5 \mathrm{~min}$ at $85^{\circ} \mathrm{C}$ and analyzed on $4-12 \%$ pre-cast SDS-PAGE gels (Invitrogen, Carlsbad, CA, USA). The gels were stained overnight in colloidal Coomassie staining solution and de-stained with $25 \%$ of methanol for at least $3 \mathrm{~h}$ and subsequently with $\mathrm{H}_{2} \mathrm{O}$ until the background was clear (Neuhoff et al. 1988).

The cow saliva was deglycosylated by incubation with deglycosylation mix II (P6044) in deglycosylation buffer II according to the Manufacturers recommendation by incubation at room temperature for $30 \mathrm{~min}$ followed by overnight incubation at $37^{\circ} \mathrm{C}$ (New England Biolabs, Ipswich, MA, USA).

Author contributions: All the authors have accepted responsibility for the entire content of this submitted manuscript and approved submission.

Research funding: This study was supported by the Knut and Alice Wallenberg Foundation (KAW 2017-0022). 
Conflict of interest statement: The authors declare that they have no conflict of interest regarding the contents of this article.

\section{References}

Carmody, R.N., Weintraub, G.S., and Wrangham, R.W. (2011). Energetic consequences of thermal and nonthermal food processing. Proc. Natl. Acad. Sci. U.S.A. 108: 19199-19203.

Chauncey, H.H., Henrigues, B.L., and Tanzer, J.M. (1963). Comparative enzyme activity of saliva from the sheep, hog, dog, rabbit, rat, and human. Arch. Oral Biol. 8: 615-627.

Fu, Z., Thorpe, M., Alemayehu, R., Roy, A., Kervinen, J., de Garavilla, L., Abrink, M., and Hellman, L. (2017). Highly selective cleavage of cytokines and chemokines by the human mast cell chymase and neutrophil cathepsin G. J. Immunol. 198: 1474-1483.

Gallwitz, M., Enoksson, M., Thorpe, M., Ge, X., and Hellman, L. (2010). The extended substrate recognition profile of the dog mast cell chymase reveals similarities and differences to the human chymase. Int. Immunol. 22: 421-431.

Gallwitz, M., Enoksson, M., Thorpe, M., and Hellman, L. (2012). The extended cleavage specificity of human thrombin. PloS One 7 : e31756.

Goettig, P., Brandstetter, H., and Magdolen, V. (2019). Surface loops of trypsin-like serine proteases as determinants of function. Biochimie 166: 52-76.

Goodman, B.E. (2010). Insights into digestion and absorption of major nutrients in humans. Adv. Physiol. Educ. 34: 44-53.

Guyonnet, V., Tluscik, F., Long, P.L., Polanowski, A., and Travis, J. (1999). Purification and partial characterization of the pancreatic proteolytic enzymes trypsin, chymotrypsin, and elastase from the chicken. J. Chromatogr. A 852: 217-225.

Hooton, D., Lentle, R., Monro, J., Wickham, M., and Simpson, R. (2015). The secretion and action of brush border enzymes in the mammalian small intestine. Rev. Physiol. Biochem. Pharmacol. 168: $59-118$.

Ishiguro, H., Yamamoto, A., Nakakuki, M., Yi, L., Ishiguro, M., Yamaguchi, M., Kondo, S., and Mochimaru, Y. (2012). Physiology and pathophysiology of bicarbonate secretion by pancreatic duct epithelium. Nagoya J. Med. Sci. 74: 1-18.

Janiak, M.C. (2016). Digestive enzymes of human and nonhuman primates. Evol. Anthropol. 25: 253-266.

Kageyama, T. (2002). Pepsinogens, progastricsins, and prochymosins: structure, function, evolution, and development. Cell. Mol. Life Sci.: CMLS 59: 288-306,.

McConnell, R.E., Benesh, A.E., Mao, S., Tabb, D.L., and Tyska, M.J. (2011). Proteomic analysis of the enterocyte brush border. Am. J. Physiol. Gastrointest. Liver Physiol. 300: G914-G926.

Meisler, M.H. and Ting, C.N. (1993). The remarkable evolutionary history of the human amylase genes. Crit. Rev. Oral Biol. Med. 4: 503-509.

Neuhoff, V., Arold, N., Taube, D., and Ehrhardt, W. (1988). Improved staining of proteins in polyacrylamide gels including isoelectric focusing gels with clear background at nanogram sensitivity using Coomassie Brilliant Blue G-250 and R-250. Electrophoresis 9: 255-262.

Spanier, B. and Rohm, F. (2018). Proton coupled oligopeptide transporter 1 (PepT1) function, regulation, and influence on the intestinal homeostasis. Comp. Physiol. 8: 843-869.

Thorpe, M., Yu, J., Boinapally, V., Ahooghalandari, P., Kervinen, J., Garavilla, L.D., and Hellman, L. (2012). Extended cleavage specificity of the mast cell chymase from the crab-eating macaque (Macaca fascicularis): an interesting animal model for the analysis of the function of the human mast cell chymase. Int. Immunol. 12: 771-782.

Thorpe, M., Akula, S., and Hellman, L. (2016). Channel catfish granzyme-like I is a highly specific serine protease with metase activity that is expressed by fish NK-like cells. Dev. Comp. Immunol. 63: 84-95.

Thorpe, M., Fu, Z., Albat, E., Akula, S., de Garavilla, L., Kervinen, J., and Hellman, L. (2018a). Extended cleavage specificities of mast cell proteases 1 and 2 from golden hamster: classical chymase and an elastolytic protease comparable to rat and mouse MCP-5. PloS One 13: e0207826.

Thorpe, M., Fu, Z., Chahal, G., Akula, S., Kervinen, J., de Garavilla, L., and Hellman, L. (2018b). Extended cleavage specificity of human neutrophil cathepsin G: a low activity protease with dual chymase and tryptase-type specificities. PloS One 13: e0195077. 